to radical operation, but with regard to glandular enlargement it must be remembered that this is not necessarily of a secondary malignant character, but may be of an inflammatory nature only, due to associated sepsis. Local fixity, moreover, rarely prevents radical measures, since $\bar{b}_{y}$ free division of the peritoneum along the outer border of the colon, many growths which at first sight appear too fixed may be rendered sufficiently mobile for excision. If a radical operation be definitely contraindicated then a "short-circuit" (that is, lateral anastomosis) should be performed, provided there is a sufficient length of colon below the growth to permit of approximation to the distended bowel above. without undue tension. Only. when a "short-circuit" is quite impossible must we, as a last resort and to prevent future intestinal obstruction, fall back on colostomy proximal to the growth.

Many cases, however, are already associated with intestinal obstruction when first seen, and it is imperative that this be relieved before any radical extirpation with restoration of the continuity of the bowel be attempted, since it is the universal experience of surgeons that resection of the colon in the presence of obstruction is a very unsafe procedure - the congested and oedematous wall of the bowel failing to hold the sutures properly, so that leakage at the suture line is very probable. In such cases the best course, I believe, is to perform caecostomy under nitrous oxide or local anaesthesia; only when, by this means, complete relief of the obstruction has been attained must recourse be had to exploratory laparotomy with a view to radical removal of the growth and restoration of the continuity of the bowel. If after this has been accomplished the caecostomy does not close spontaneously, a slight plastic operation will suffice for its obliteration.

\section{Cancer of the Rectuit.}

It is an extremely unfortunate fact that at the present time fully 75 per cent. of the cases coming to our hospitals with cancer of the rectum have already reached a stage much too advanced for any hope of radical operation. This is surprising when it is remembered that such growths are readily arailable to rectal palpation, and it is largely the neglect to make a digital examination of the rectum whenerer patients come complaining of rectal symptoms that is responsible for this lamentable state of affairs. Even when blood has been passed per anum it is not uncommonly too readily assumed that it is due to the commonest cause-piles-without a digital examination.

\section{Symptoms.}

The early symptoms of rectal cancer are of ten indefinite, and are essentially those already described for growth of the colon. A patient whose bowels have previously acted regularly, on going to morning stool and thinking to have a normal motion, finds ir:stead that he passes mostly bloodstained nucus and flatus, and that he has to repeat his visit very shortly, possibly for several times, before he obtains relief. This "spurious diarrhoea" is really indicative of constipation. Severe bleeding from the rectum is uncommon except in an advanced stage, but occasionally it may be an early symptom, and then, fortunately, alarms the patient and leads him to seek advice in an early and operable stage. Pain is often completely absent in the carly stages; if present it may be felt in the rectum, in the sacrum, or over the lower abdomen. An alteration in the shape of the faeces, chiefly in the direction of flattening, is sometimes noticed early, especially in the stenosing type of growth and when situated near to the anus; with a high growth the faeces may be remoulded in the rectum after passing through the stricture and thus appear of normal shape.

\section{Diagnosis and Treatment.}

Suspicion of rectal trouble having been aroused, a digital examination should be made forthwith, and should it prove negative a sigmoidoscopic examination should follow, since the commonest site of growth is the recto-sigmoid junction, and this may not be reached by the examining finger. Bimanual examination with the forefinger of one hand in the rectum and the other hand flat on the lower abdomen sometimes enables an otherwise impalpable growth to be discovered. By digital examination is determined, not only the presence of a growth in the rectum, but also the extent to which it has already involved the adjacent structures-prostate, bladder, vagina, uterus, and sacrum. If not fixed to any of these, and if no cnlargement of the liver can be felt (or of the inguinal glands in cancers involving the anal canal), then the question of a radical operation must be considered. The possibility of this cannot be finally determined until, as the first opcrative step, the abdomen has been opened and the presence of metastasis in the liver or peritoneum, or the too extensive involvement of lymphatic glends, definitely excluded. It has, unfortunately, been my experience on more than one occasion to find that with a comparatively small and freely mobile rectal growth-and presumably, therefore, an early onea secondary deposit in the liver has been disclosed on opening the abdomen, and the contemplated radical operation thereby prevented. We need not to-day enter into the much discussed question of the relative merits of the two chief radical operative procedures at present in vogue: (1) the abdomino-perineal operation perfected by Miles, and (2) perineal excision following a preliminary colostomy; they both entail a permanent iliac anus as part of the price the patient is called upon to pay for any hope of cure of a rectal cancer. Possibly, in tho future, with cases presenting themselves at an earlicr stage and with a better selection of cases, it may be feasible to remove the rectum with preservation of the sphincters and restoration of the continuity of the bowel, but at present such is not to be recommended.

If a radical operation be decmed impracticable, either because of the local extent and fixity of the primary growth or because of the presence of metastases, then tho question of a palliative colostomy has to be considered. This should certainly be performed wherever there is any evidence of actual or of shortly threatened obstruction, and considerable relief may be expected therefrom. In the ulcerative types of growth obstruction is not a marked feature, and the patient's chief distress is occasioned by the profuse discharge of blood and muco-pus from the growth, necessitating the passage of very frequent stools; although by diverting the faeces from the growth colostomy may be reasonably expected to diminish the amount of this discharge, yet sufficient may remain to cause patients to express disappointment at the smali measure of relief afforded them by the operation, and this should be fully explained to them before their consent to colostomy is obtained.

REFERENCES.

1 British Mrdical Jotraxal, Norember 14th, 1925. 2 Journ. Amer. Med. Assoc., 1924, Ixxxiit, p. 1976: 3 Britssh MFDicil Jocrnal, January 2nd, 1926.

\section{THE THYROID GLAND IN THE FULL-TIME HUMAN FOETUS AND IN THE NEWLY BORN INFANT.}

$$
\text { (With Special Plate.) }
$$

$\mathbf{B Y}$

IAN MURRAY, M.D.

DISPENSARY PHYSICIAN, VICTORIA INFIRMARY, GLASGOW. (From the Institute of Physiology, University of Glasgow.)

\section{Introduction.}

Varrous descriptions have been given of the appearance of the thyroid gland of the human subject about the time of birth. The majority of workers have recorded a condition very different from that seen in the normal adult gland, and several have advanced hypotheses to explain it.

It would seem that typical colloid appears at some period of intrauterine life. Elkes (1904) described it in foetuses from $4 \frac{1}{2}$ to $6 \frac{1}{2}$ months, Livini (1922) in embryos of 62 to $66 \mathrm{~mm}$., while Müller, Peremeschko, and Brechat, cited by MérozTydman (1910), found it present, tho first in a foetus of 5 months, the others at a later period. Wölfer (1880), however, was of the opinion that colloid formation did not commence until the end of foetal life or even till after birth. Treating this investigation from the chemical standpoint, Marine (1922) states that the iodine content of the thyroid increases with the increasing age of the foetus. Fenger 
(1913, 1915) examined the iodine content of a large serins of foetal cattle, pigs, sheep, and man, and came to the same conclusion.

Immediately after birth, according to some olycervers, a very striking change in the histological appearance of the thyroid occurs. Zielinska (1894) found solid collections of cells filling the vesicles without any sign of colloid. Elkns gave a similar description, and emphasized the difference between the foetal gland and that of the newly born.

Méroz-Tydman examined a series of thyoids from stillborn and newly born children, and found that in both some glands were made up of elongated or rounded heaps of epithelial cells closely pressed together, while others showed vesicles with desquamating cells and no colloid; others again were composed of almost normal-looking resicles containing a little colloid, in which, howerer, were so many vacuoles that it had the appearance of a thin network. Hesselberg (1910) considered that the normal appearance of the thyroid, at least during the first week of life, is one of empty vesicles and desquamating cells.

Maurer, cited by Hesselberg, on the other hand, found that after birth colloid is sometimes present. Elkes drew his conclusion, that the thyroid at this age is colloid-free, from the examination of a series of thyroids from newly born children. There was one exception, howerer, which showed well differentiated vesicles filled with colloid. Garnier (1899) found no great difference between the thyroid of the newly born and that of the full-time foetus. Hesselberg also was doubtful if there was any marked difference, as she found, in three out of nine foetuses from 7 to 9 months, the desquamated condition of the gland, which she considered the normal appearance in the newly born. Cooper (1925) stated that during the first two weeks after birth the thyroid shows little difference from that of the full-time foetus, but that practically all the resicles are empty.

Four theories as to the cause of this change in the thyroid after birth have been suggested. Wölfer, after examining a series of glands from fecble and stillbori children, and finding that they had few or no resicles and no colloid, considered that, as this condition resembled the state of the thyroid before colloid formation was begun, the cause of the appearance after birth was arrested development of the gland.

De Quervain (1904) suggested that the desquamation of the epithelial cells might be due to disease in the child. Perrando, cited by Hesselberg, and Flkes found a similar condition in thyroids taken from children who had suffered from congenital syphilis. Garnier, in the cuurse of an investigation on the effects of infectious diseases of the thyroid gland, found, however, that desquamation was present in the thyroid of a stillborn child, otherwise normal, after a prolonged labour.

Elkes was of the opinion that some metabolic change, taking place immediately after birth, might account for the alteration in the thyroid. Hesselberg, howerer, found no evidence of desquamation in the glands of various animals killed and examined shortly after birth, and disagreed with Elkes's theory, thinking that as some similar metabolic change probably occurs in the lower animals this should, if the hypothesis were correct, cause some alteration in their thyroids also.

Hesselberg held the view that the disappearance of colloid and the desquamation of the epithelial cells was due to damage to the thyroid during birth, by reason of the relative narrowness of the human birth canal. She holds that this theory would expiain Garnier's results mentioned above.

\section{Present Investigation.}

The present investigation was undertaken with a riew to determining whether the condition of the thrroid at birth might be related in any way to the state of development of the child, or whether it might be due to autolysis or post-mortem degeneration. Neither of these possibilities has apparently been inquired into, as no reference to either has been discovered in the literature. To obtain some idea of the effects of autolysis on the thyroid gland before examining the human thyroids described later, observations were made on the post-mortem changes in the thyroid of the dog.
A. Stridy of the Degenerative Process in the Thyroid.

Seven experiments were carried out with a view to discovering the effect of autolysis in the thyroid. Cruickshank (1911) carried out similar experiments with liver and kidney, and his method was followed. After trying various media he found that he obtained the best results by keeping the tissue in a moist chamber, and in several of his experiments he was successful in obtaining autolysis similar to that seen in the body and in foetal tissues.

Previous to the removal of the thyroid a sterile Petri dish was prepared in the foot of which was a layer of blotting paper soaked in salt solution, both paper and solution having been sterilized. The neck of the $\operatorname{dog}$ was then shaved and washed carefully-no antiseptic could be used as autolysis is retarded by its presence. The two thyroids were removed and transferred as quickly as possible with sterile instruments to the Petri dish. Each thyroid was then cut with a sharp knife into four parts. One part was removed and fixed at once in formalin as a control, and the dish was closed. In some cases the Petri dish was kept at room temperature-to compare with the rate of change in the thyroid of a foetus kept in the mortuary - and in others it was placed in an incubator kept at a constant heat of $37^{\circ}$. At intervals of twenty-four hours a piece was removed and fixed. The tissues were prepared by the usual paraffin method, cut, and stained with haemalum and eosin. The greatest care was taken to maintain sterility, but it is doubtful if this was successful, and it certainly failed in some cases which showed bacterial growth round the margins. Cruickshank also experienced very great difficulty in keeping the organs sterile, and bacteriological examination proved that in about half his experiments all his precautions had been of little avail.

In the case of the thyroids at room temperature the degenerative process took place gradually throughout the week, the duration of the experiment. The first change was the appearance of vacuoles round the margin of the colloid masses in the vesicles, which had shrunk somewhat. At this stage the vesicular cells are still cubical and ranged regularly round the vesicle. This condition is illustrated in Fig. 2, which shows such a thyroid forty-eight hours after removal. Fig. 1 shows the state of the gland immediately after removal from the body.

The lining cells of the vesicles next become detached from the basal membrane and all the colloid disappears. As the process of degeneration progresses the cells become separated from each other and lie free in the lumen. As this proceeds the section takes on a much more cellular appearance. The vesicles become small, and less and less distinct until their outline, marked by a thin strand of connective tissue, can only with difficulty be made out. The interior of the resicles is ultimately packed with epithelial cells, many of which appear as large rounded pink-staining cells with a dark nucleus. The thyroid shown in Fig. 3 illustrates this state. It was fixed seven days after removal, during which time it had been kept at room temperature.

The rate of degenerative change in the thyroids kept in the incubator at $37^{\circ}$ was about three times that of those kept at room temperature. The same process was observed, but the change at the end of twenty-four hours was greater than that in those kept in the cooler temperature for forty-eight hours. In the specimens kept in the incubator further changes than those described above were observed. Gradually the cells and nuclei degenerated until the section presented an almost homogeneous pink appearance. For the present purposes, however, only the changes described and illustrated above are of interest.

Thers is one other point to which attention may be directed. Fig. 1 shows a perfectly normal thyroid of a dog with large well filled vesicles, while in Fig. 2 the same thyroid is shown after forty-eight hours' degeneration. In the latter racuoles are very noticeable, although there are none present in the freshly fixed gland. It would appear that these vacuoles resulted from a process. of degeneration, and this is confirmed by the work described below on the thyroid of the foetus.

Many views have been expressed as to the cause of the appearance of the vacuoles which were frequently observed in the colloid. Cowdry (1922) and others have ascribed them to shrinkage of the colloid in preparation. Jackson 
(1916) believed they. were connected in some way with the process of colloid formation, while Cooper (1925) has advanced the opinion that they may be due to absorption of colloid into the circulation. Neither of the last two theories, however, could account for the occurrence of racuoles post mortem, and if Cowdry's hypothesis applies here, it would seem, as there was no shrinkage in the freshly fixed gland, that there must be some chemical change in the colloid substance before this can occur.

\section{B. Examination of a Series of Young Human Thyroids.}

At the Glasgow Royal Matcrnity Hospital routine postmortem examinations are performed on all infant corpses, whether the child has been stillborn or has lived. Full details as to size and development, as also to the postmortem findings in the rarious organs, are recorded. Through the kindness of Dr. Norman Cruickshank I was permitted to examine the thyroid from 70 of these casss.

The gland was fixed in formalin after removal and weighing, and was embedded by the paraffin method, cut, and stained with haemalum and eosin.

Details as full as possible were obtained in each case, special note being taken of the state of development, as it was intended to correlate this, if possible, with the histological findings in the thyroid. The age of the foetus was calculated from the date of the last reenstruation to the date of birth. The former, however, was often difficult to ascertain, and many of the ages thus obtained were only approximate. Accordingly no great reliance can be placed on this. A much more accurate idea of the state of development can be obtained by examination of the condition of the various centres of ossification. For this purpose the following were noted: the number of centres present in the mesosternum, and the size of the centres in the astragalus, the os calcis, the lower end of the femur, and the upper end of the tibia. The weight, length, and sex of the child, and the number of the pregnancy, were also noted.

As the possibility had to be taken into account of the appearances of the thyroid being due in some cases to autolytic change, the time from death or stillbirth until the time of post-mortem examination was noted. This could be obtained accurately in the case of children who had lived, but in the others it was very difficult, and usually impossible, to find out how long the foetus might have been dead in utero. As the majority of craniotomies were performed on account of contracted pelvis, and as in many such cases the child is alive until the operation is undertaken, it was thought that a more accurate estimate of the time that the child had been dead before examination might be obtained in the instances where this was done than in the other stillbirths, and these cases were consequently segregated. There cannot, of course, be the same exactitude as when the child had lived, but probably nore than with the remaining stillbirths.

I am inclebted to a house-surgeon for three thrroids which he removed and fixed immediately after delivery. In these cases craniotomy was performed on living foetuses, the ninthers' pelves being greatly contracted. The glanis obtained thus were therefore free from any suspicion of pest-moitein change.

\section{Histological Examination.}

The appearances found in the thyroids were very varied. Some were made up of colloid-containing vesicles, some of empty vesicles, while other's presented a solid cellular appearance quite unlike that normally associated with this giand. In this description they may conveniently be grouped into two classes-those containing colloid and those free of colloid.

1. Glands containing Colloid.-Into this class fall $₹ 2$ of the thyroids examined. The gland was composed of vesicles lined with cubical epithelium and filled with colloid which stained well. Some showed a certain amount of intervesicular tissue, but where tho vesicles are small this is only to be expected as the result of the section passing tangentially through the walls of some vesicles. The vesicles varied in size, but were always much smaller than in the adult gland. Irig. 4 shows the low-power view, and Fig. 5 the appearance, seen under high power, of the sections of the thyroids which were fixed immediately after death. These are more or less typical of all the glands included in this group, although some showed more colloid. They were selected for illustration as there can be no doubt about their freshness. There was little difficulty in separating this group from the next, as the presence of the colloid was in erery case noticeable at a glance. As regards vascularity, it was found that in some thyroids the capillaries were congested, while in others they were more or less empty. It seems possible that the congestion described by some observers as being invariably present may be due to the character of the labour.

2. Glands containing no Colloid.-As has been indicated, these thyroids raried from a condition in which there was morely an absence of colloid to a state in which vesicles as such could scarcely be recognized. For descriptive purposes, however, they may be divided into three types:

A. In a few thvroids there are still traces of colloid in the vesicles. This, however, stained faintly and contained large vacuoles, which were often so numerous that all that remained of colloid was a thin network between these vacuoles. The walls were lined with cubical cells more or less regularly arranged, though here and there they had become detached and were escaping into the lumen (Fig. 6).

B. Many of the sections presented a characteristic clear appearance. The glands contained no colloid and the protoplasm of the cells stained rather faintly. Vesicles were clearly discernible, but many of the cells composing their walls had separated from the basal membrane. When they still retained their attachment they were of more columnar shape (Fig. 7).

C. A considerable number of the thyroids had a very cellular appearance. In many cases it was only with difficulty that the outline of vesicles could be distinguished, marked out ly a thin line of connective tissue cells. The vesicles were filled with desquamated cells of more or less rounded shape (Fig. 3). As in the thyroids of type $B$, the protoplasm of the cells stained more faintly than in those glands which contairied colloid, while the nuclei were much darker. In this group, : in the first, some glands were very congested, while in other's there were few blood cells visible.

For brevity of description, in the accompanying table the thyroids have been classed in three groups: Groul) I is made up of the thyroids containing colloid; those colloidfree glands described above as types $\mathbf{A}$ and $\mathbf{B}$ are collected together into Group II ; while the remainder (type () form Group III.

\section{Summary of Results.}

A. Children who Liced.-Sixteen of the thyroid glands examined were taken from children who had survived for some time after birth. This time varied from a few hours to ten dars. Of these, 8 were found to be of the type described above as Group I, 5 of Group II, and 3 of Group III. Comparison of the data collected about each case showed great variation in the age, weight and length, state of ossification, duration of life, of the infants whose thyroids were classed together in one group. Moreover, similar variation occurred in all thrce groups. One fact, however, may be observed-namely, that in every case in which colloid was found to be present the postmortem examination had been carried out within twentyfour hours of death, whereas in the others with only one exception this was delayed for two or three days.

B. Stillbirths: C'raniotomies. - In this class, while similar variations were found in the age and development,

\begin{tabular}{|c|c|c|c|c|}
\hline \multirow{2}{*}{ Class. } & \multirow{2}{*}{$\begin{array}{c}\text { No. of } \\
\text { Thyroids } \\
\text { Examined. }\end{array}$} & \multirow{2}{*}{$\begin{array}{l}\text { Type of } \\
\text { Thyroid. }\end{array}$} & \multicolumn{2}{|c|}{$\begin{array}{l}\text { No. of Days from Time of } \\
\text { Death until Time of Post- } \\
\text { mortem Examination. }\end{array}$} \\
\hline & & & Averase. & $\begin{array}{l}\text { Standard } \\
\text { Deviation. }\end{array}$ \\
\hline $\begin{array}{l}\text { A. Children who } \\
\text { lived. }\end{array}$ & $\begin{array}{l}8 \\
5 \\
3\end{array}$ & $\begin{array}{l}\text { Group I } \\
\text { Group II } \\
\text { Group IfI }\end{array}$ & $\begin{array}{l}0.75 \\
2.0) \\
2.33\end{array}$ & $\begin{array}{l}0.250 \\
0.633 \\
0.481\end{array}$ \\
\hline $\begin{array}{l}\text { B. Still bir ths }- \\
\text { craniotomies }\end{array}$ & $\begin{array}{l}6 \\
3 \\
5\end{array}$ & $\begin{array}{l}\text { Group I } \\
\text { Group II } \\
\text { Group III }\end{array}$ & $\begin{array}{l}0.63 \\
1.66 \\
3.80\end{array}$ & $\begin{array}{l}0.567 \\
0.494 \\
0.400\end{array}$ \\
\hline $\begin{array}{l}\text { C. Remaining } \\
\text { stillbirths. }\end{array}$ & $\begin{array}{r}8 \\
6 \\
26\end{array}$ & $\begin{array}{l}\text { Group I } \\
\text { Group II } \\
\text { Group III }\end{array}$ & $\begin{array}{l}1.18 \\
1.33 \\
2.38\end{array}$ & $\begin{array}{l}0.498 \\
0.471 \\
0.836\end{array}$ \\
\hline Tota!s. & $\begin{array}{l}22 \\
11 \\
34\end{array}$ & $\begin{array}{l}\text { Group I } \\
\text { Group II } \\
\text { Group III }\end{array}$ & $\begin{array}{l}0.87 \\
1.64 \\
2.58\end{array}$ & $\begin{array}{l}0.427 \\
0.534 \\
0.741\end{array}$ \\
\hline
\end{tabular}


it was also noted that the six thyroids belonging to Group I were taken from infants on whom the post-mortem examination had been performed within twenty-four hours of delivery. In three cases where the thyroid showed desquamation of the epithelial cells and no colloid (Group III) the necropsy had taken place from one to two days after delivery, and in five, in which this was delayed for three or four days, all the glands showed vesicles filled with desquamated cells (Group III).

C. Remaining Stillbirths.-In 8 cases the thyroid showed the appearances of the Group I type. On 6 of these the post-mortem examination was performed within twenty-four hours, and on the other 2 within two days. In the case of the 6 thyroids which belonged to Group II the necropsy was carried out from one to two days after birth, whils with those of Group III this varied from one to four days. As with the other two classes, great variation occurred in the other factors considered, with none of which could the thyroid appearances be correlated.

These results are summarized in the accompanying table. The cases are arranged according to the histological appearances of the thyroid, and for each group the average number of days from death or stillbirth until the time of the post-mortem examination is given, together with the standard deviation. It will be seen that in each section this time is shortest in the case of the Group I thyroids, and longest with those of Group III. This is very apparent when the averages for all the thyroids of each group are totalled. In the cases where the gland was of the Group I type the autopsy was performed 0.87 day after death or stillbirth, while with Group II this was 1.64 days, and with Group III 2.58 days.

Thus it appears that these striking variations in the histology of the thyroid cannot be due to variations in development, whether reckoned by age, weight and length, or extent of ossification. Neither do they seem to le related to the sex of the child, or to the number of the pregnancy. Thus one has to consider whether these variations may be accounted for by the differences in the time between the death of the child and the fixation of the thyroid-that is to say, whether they can be due simply to degenerative changes.

The thyroids from the three cases of craniotomy in which the glands were fixed within a very short time of cleath all present a similar appearance, and all show a considerable amount of colloid-that is, they belong to the type described as Group I. No degeneration can have taken place, and consequently these may be looked on as normal, although, as already stated, they do not conform exactly to the appearance found in the adult gland. 'Taking this standard as normal, it will be seen that in all cases in which the gland was fixed within twenty-four hours of death the thyroid may be regarded as normal, while in practically every case in which it remained in the body for a longer period it may be said to be abnormal. The exceptions to this are: (1) a few cases where the normal appearance was found in thyroids removed two days after death, and (2) seven of the cases of stillbirth other than craniotomies (Class C) where the gland belonged to Group II or Group III. The latter may be accounted for by the fact that from the clinical notes in these cases r.o estimate could be formed as to how long the child may have been dead in utero. As has been seen from the experimental work already described, autolytic change takes place at a greater rate at blood temperature than at room temperature. Thus if the child were dead in utero for a comparatively short time it is highly probable that by the end of twenty-four hours after delivery any degenerative change would be very much more advanced than if the child had lived till the time of birth. This, then, may be the reason for the colloid-free condition appearing so early in these eases. In practically all cases in which the necropsy was performed two days after birth, as also in all cases where this was done at a later date, the thyroid presents this abnormal condition.

To sum up, it will be seen that the type of thyroid clescribed as being of Group I, which appears only when the gland had been fixed within a short time of death, is to be considered the normal histological structure of the thyroid at the time of birth. Group II and Group III thyroids are to be looked on as abnormal, and it will be seen that the appearances of these types of thyroid resemble those described as occurring in the degenerating thyroid of the dog. Taking this together with the finding that these types were seen when the gland had not been fixed until later than those of Group I, we may conclude that Group II represents a degenerative change in the thyroid, and Group III that change still farther advanced.

Further evidence that the colloid state is normal at the time of birth, and that desquamation is abnormal, is obtained by examination of the thyroid of experimental animals. As already mentioned, Hesselberg found that tho thyroid in dogs, cats, and rabbits immediately after birth were well filled with colloid and showed no sign of the desquamation, which she considered to be normally present in the thyroid of the child during the first three weeks of life. I have on several occasions examined the thyroid of full-time guinea-pigs remored by Caesarean section, and have invariably found a similar condition.

Hesselberg sought to explain the difference in the thyroid at birth in man and in animals, in that that of the former showed desquamation and the latter did not, by suggesting that, owing to the narrow birth canal in the human subject, the thyroid was injured during delivery. If this were so we would expect to find desquamation more frequently in a first-born child, and not so often in the children of a multipara, when the birth is usually easier; but this is not borne out by this work. Moreorer, a large proportion of stillbirths are due to difficult labour, yet a considerable number of such in this series had normal thyroids. Garnier found that after a prolonged labour the child's thyroid showed desquamation. In such a case, however, it would seem that there was every possibility of the child being dead in utero for some considerable time, in which case autolysis would account for the change ne described.

\section{Coxchusions.}

1. The thyroid gland of the full-time human foetus, an! also of the newly born infant, appears to be composed normally of small vesicles lined with eubical epithelium and filled with colloid which stains well. The glands may or may not be congested.

2. When variations from this conception of the normal are observed it seems probable that they may in many cases be due to post-mortem degeneration.

3. The changes which occur in the thyroid gland post mortem may be summarized thus. First, vacnoles appear in the colloid which vilimately disappear completely. Tho epithelial cells then become separated from the basal membrane. Eventually the vesicles become filled with desquamated cells and the gland presents a solid cellular appearance.

4. As the formation of vacuoles in the colloid may take place after death, these cannot always be regarded as evidence of activity on the part of the thyroid.

5. No relationship was found to exist between the condition of the thyroid in the full-time foetus and the development of the child as reckoned by the extent of ossification.

This work was commenced during the tenure of a Carnegie Research Scholarship, and was carried out in the Institute of Physiology, at the University of Glasgow. I wish to thank Professor $\mathrm{D}$. Noël Paton for kind help with, and interest in, the work, and Dr. Norman Cruickshank for permission to use the records of the Pathology Department of the Royal Maternity
Hospital, I am greatly indebted to Mr. John Bell for the care Hospital, I am greatly indebted to Mr. John Bell
which he took in the preparation of the photographs.

\section{REFERENCES.}

Cooper, E. R. A. (1925): The Histology of the More Important Human Endocrine Organs at Various Ages. Oxford Medieal Publications. cowdry, E. V. (1922): Art. in Endocrinology and Metabolism, Appleton, New York, i, 215

Cruickshank, J. (191i) : Journ. Path. and Bact., xvi, 167.

De Quervain, F. (1904): Akute nicht eitrage Thyreoid itis (cit. Hesselberg) lkes, C. (1904): Der Bau der Schilddrusse um die Zeit der Geburt (cit. Hesselberg)

Fenger, F (1913): Journ. Biol. Chem., xiv, 397; ibid., 1915, xx, 695 Garnier, M. (1899): La glande thyréoide dans les maladies infecticuscs. Paris (cit. Hesselberg).

Hesselberg, C. (1910): Frankfüter Zeit. $f$. Path., v, 322

Jackson, C. M. (1916) : Amer. Journ. Anat., xix, 305.

Livini, F. (1922): Arch. Ital. di anat. e di embriol., xviii, 522.

Mároz-Tydiman (1910): Rev. Héd. de la Suise Romande, xxx, 526. Wölfer (1880): Uber die Entucickelung und den Bau der Schilddrusec (cit. Hesselberg).
Zielinska, M. (1894): Virchou's Archir, cxxxvi, 170. 
JAN. I, I927] IAN MURRAY: THE THYROID GLAND IN THE FOETUS AND NEWLY .BORN. [MEDICAL JoURAaL
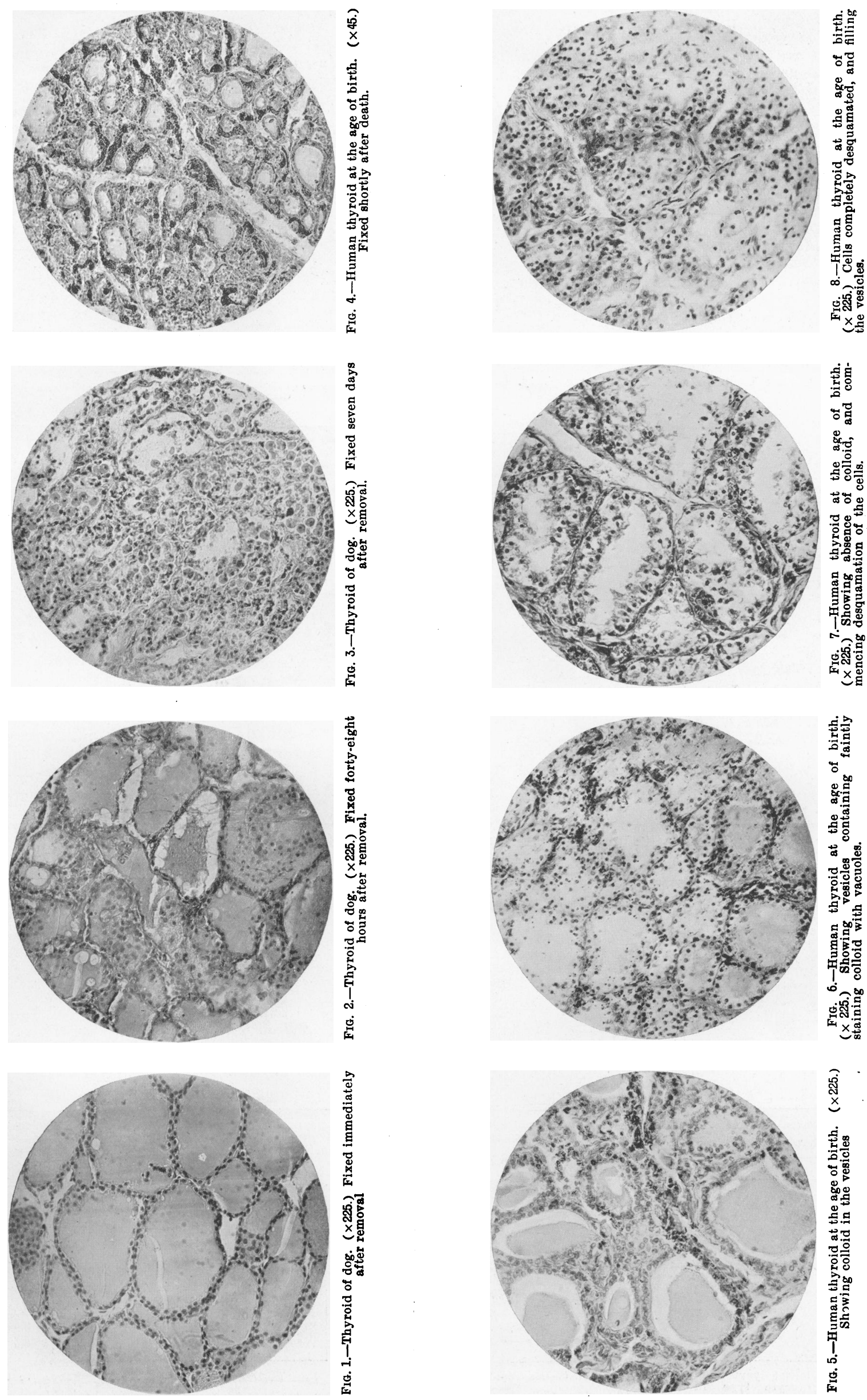